\title{
O design de periódicos científicos on-line e a visibilidade da ciência na web
}

\author{
Electronic journals design and the visibility of the science on the Web
}

Ana Cláudia Gruszynski e Raquel Castedo

design, periódicos científicos on-line, ciência

\begin{abstract}
A produção editorial contemporânea revela as tensões existentes entre o tradicional mundo impresso, com limites físicos de informação, e o espaço on-line como um contínuo informativo. Este artigo analisa novas estratégias de visibilidade da ciência na web tratando de tópicos como identificação, descrição e intercâmbio de recursos eletrônicos na sua relação com o design e com a qualidade e credibilidade das publicações científicas. Destaca características singulares do processo editorial bem como do público-leitor dessas publicações.
\end{abstract}

design, on-line journals, science

The contemporary editorial production reveals the tensions between the traditional print world, with its physical limits of information, and the on-line space as a continuous place for information. This article argues about science visibility on the web, addressing topics such as identification, description and exchange of electronic resources in relation to design and to the quality and credibility of scientific publications. The unique characteristics of the editorial process as well as public-readers of these publications are taken into particular account.

\section{Introdução}

A ampliação de recursos de armazenamento e disseminação de informação científica passa pelo controle e incremento de seus fluxos. Diante da quantidade de dados disponíveis para pesquisa na web, a racionalização dos processos de busca, consulta e navegação é fundamental para evitar a sobrecarga cognitiva. Se, por um lado, o suporte eletrônico e em rede oferece condições para o desenvolvimento de bibliotecas digitais, repositórios e periódicos científicos eletrônicos, de outro, as diferentes formas de interação mediadas pelas tecnologias desafiam a comunidade científica na sua apropriação, envolvendo valores e hábitos arraigados pela cultura do impresso.

Este artigo sistematiza e discute aspectos relacionados à edição de periódicos eletrônicos na Internet na contemporaneidade. Com base na discussão bibliográfica, problematiza a noção de visibilidade, que nesse contexto, passa ao primeiro plano, uma vez que para as revistas científicas - principais veículos de comunicação formal dos resultados de pesquisas originais -, é estratégica no seu desenvolvimento editorial. Tal condição apóia-se em duas dimensões principais: construir uma reputação de qualidade e credibilidade em uma área de conhecimento e ser indexado em índices de prestígio nacional e internacional. Um fator alimenta o outro e vice-versa, pressionando o periódico, ao longo de sua evolução, a alcançar e manter a condição de veículo preferencial e confiável para publicação, leitura e citação sistemática de resultados originais de pesquisa. Tratase de um círculo que atualiza e, ao mesmo tempo, refrata determinada posição de uma comunidade científica, de usuários que são seus próprios autores e leitores. (Packer \& Meneghini, 2006)

Se qualidade e credibilidade são características intrínsecas a uma publicação de referência, sua visibilidade depende também da capacidade de ser acessado em bases de dados e índices, o que se relaciona diretamente com a atividade de design. Questões tecnológicas passam a ser determinantes na localização das informações, geralmente realizada através de mecanismos de busca e indexação. Para facilitar esse processo, associaram-se metadados aos documentos, que 
são dados que descrevem informações sobre cada recurso disponível. Estes têm a função de facilitar a recuperação de informações eletrônicas, fornecendo meios de identificação e organização, tornando possível a associação de fontes diferenciadas e heterogêneas (Ferreira, Modesto \& Weitzel, 2006).

No âmbito da edição de periódicos eletrônicos, portanto, o termo visibilidade não se restringe apenas a características relacionadas à clareza do layout de um documento. A acessibilidade e 0 desenvolvimento de recursos otimizados para serviços de pesquisa compõem um conjunto de fatores que devem fazer parte do planejamento editorial de uma publicação, sobretudo no que se refere ao design.

Devemos levar em consideração também que a forma como as revistas científicas apresentam a informação vem se transformando gradualmente desde o surgimento do Journal de Sçavans, França, janeiro de 1665, e do Philosophical Transactions of the Royal Society, Inglaterra, março de 1665. As transformações da comunidade científica, suas exigências e interesses, bem como a tecnologia à sua disposição, foram gradualmente conformando as práticas editoriais dos periódicos, voltadas a um público leitor bastante especializado.

Levando em consideração o sujeito leitor, destacamos que o nível de familiaridade que o texto tem com o seu universo cultural permite que ele utilize o mecanismo de antecipação, delineando a leitura a partir de hipóteses sugeridas pelo texto e pelo contexto. A organização dos conteúdos, portanto, conformada nos signos tipográficos que constituem a escrita, permite uma leitura "preliminar" que se ancora em uma estrutura compreensiva elaborada de acordo com uma prática e um reconhecimento de modos de funcionamento textuais apreendidos ao longo de vários contatos com textos. (Vigner, 1988:32) A leitura do texto científico, enquanto projeto, consiste em uma finalidade distanciada do leitor, exterior a si. Demanda uma conduta mental dirigida uma vez que visa à ação, caracterizando-se como uma situação funcional. 'Sendo assim, o funcionamento mental é do tipo analítico, seqüencial, convergente. A leitura é sustentada por uma atividade de raciocínio, de controle e de seleção de informações, colocando-os a serviço do objetivo pretendido'. (Gaté, 2001:32)

Como leitor principal de revistas científicas, encontra-se o pesquisador, que é também autor desse tipo de conteúdo. Meadows (1999) afirma que para os cientistas o requisito mais importante de um documento eletrônico é sua facilidade na produção de cópias impressas de qualidade. Isso refletiria o fato de que muitos leitores pensam que lidar com o texto eletrônico é mais difícil do que com o texto no papel. $\mathrm{O}$ autor defende ainda que algumas facilidades do meio impresso - como a consulta de informações folheando páginas impressas em relação a navegação hipertextual do texto eletrônico, ou a questão da portabilidade e a anotação do conteúdo serem muito mais fáceis no papel - levariam a crer que a leitura de textos eletrônicos ainda seja, em geral, um processo menos satisfatório do que a leitura no suporte em papel. Apesar de passados quase dez anos desde que tais afirmações foram feitas por Meadows, as práticas de leitura de revistas científicas ainda permanecem ancoradas nessas bases.

Outro fato importante apontado pelo autor é que esses leitores não estariam alheios ao potencial da hipermídia no que diz respeito à criação de novos projetos gráficos para o texto eletrônico em relação ao meio impresso, entretanto a maioria espera que as publicações digitais, pelo menos inicialmente, se assemelhem a seus equivalentes em papel. Questões de natureza ergonômica continuam ainda hoje como principal limitador para a leitura em tela, mais do que na página impressa, o que indicaria a primeira como um processo menos satisfatório do que a segunda. Apesar dessas considerações, Meadows (1999:158) ressalta que se existir motivação suficiente, "como, por exemplo, o rápido acesso a uma grande variedade de informações, os leitores aceitarão as limitações.'

Gruszynski (2007:120) resgata abordagens acerca da escrita e da leitura destacando-as como atividades 'constituídas por um conjunto de práticas e de condições que têm caráter histórico'. A autora retoma o trabalho de David Olson (1997), para quem a variedade de tais práticas está relacionada aos espaços do individual e do social, bem como as considerações de Roger Chartier (1996), que afirma que o ato de ler resulta de tensões estabelecidas entre dois conjuntos de fatores: (1) os relacionados aos leitores e às comunidades de leitura nas quais estão inseridos; e (2) os relacionados aos textos e a sua materialidade.

No caso dos usuários de revistas científicas, estes em geral têm hoje a possibilidade de ler um artigo tanto em papel, quanto na tela do computador. O que eles decidem fazer está sujeito a preferências pessoais - que passam pela facilidade/dificuldade de acesso -, bem como a características do grupo de pares do qual fazem parte. Atualmente, as formas de apresentação impressa ou eletrônica acabam sendo complementares. Muitos leitores realizam pesquisas on-line 
em busca de novos textos, mas preferem consultar, em uma leitura mais atenta, o material em papel - que pode ser tanto o fascículo impresso e montado industrialmente, quanto uma versão de impressora doméstica. Deste modo, a transição do impresso ao eletrônico não reflete a total eliminação do uso do primeiro em relação ao segundo.

Em ambos os casos, o design forja relações que coordenam palavras e imagens, dentre uma extensa lista de fatores humanos e técnicos, comunicando pela tradução do invisível em visível (Frascara, 2006). No início da década de 1990, durante o estágio primitivo da mídia com base na tela, os designers gráficos entraram em uma área de turbulência, onde sua profissão não estava mais preocupada apenas com palavras e imagens estáticas, mas também englobou som e imagens em movimento. (Heller \& Drennan,1997) O designer digital passou a examinar o ponto onde meio impresso e digital se encontram direcionando a transição da mídia fundamentada no papel para a fundamentada na tela. A mídia interativa não está mais restrita às definições tradicionais de palavra e imagem, forma e lugar (Helfand, 1996). Não há, portanto, comunicação da ciência que prescinda de design, porque a conformação material é condição essencial para sua existência. Nesse sentido, as alterações no campo do design com a criação da tecnologia digital influenciam diretamente a produção de periódicos científicos no novo meio.

\section{O design e a visibilidade da informação científica na Internet}

No âmbito dos periódicos científicos eletrônicos, o design de informação dará conta de organizar e apresentar as informações a um público bastante específico, já que autores e leitores - os pares compartilham repertório, interesses e tensões comuns. Em sentido amplo, temos o que caracteriza o caráter científico dessas publicações que, por sua vez, desdobra-se em valores vinculados a áreas de conhecimento - ciências humanas, sociais aplicadas, saúde, etc. - que compõem perfis singulares.

O design de sites estará centrado em garantir que nenhum aspecto da experiência dos usuários nesse espaço aconteça sem que os designers que o projetaram estejam conscientes disso. Para Jesse James Garrett (2002), isso significa ter em conta todas as possibilidades de cada ação que o usuário possa fazer e entender suas expectativas a cada passo no caminho desse processo. $O$ autor aponta cinco níveis gerais - ou planos - que formam as camadas dessa experiência, de modo que se possa entender como as decisões dos projetos de sites para a web são tomadas. Citados inicialmente do plano mais concreto ao mais abstrato, são os níveis: de superfície, de esqueleto (skeleton plane), de estrutura, de escopo e de estratégia.

Na superfície, se vê uma série de páginas da web compostas de imagens e texto. Certas imagens são clicáveis, executando algum tipo de função no site, por exemplo, entrar em alguma área específica. Outras são apenas ilustrações, como uma fotografia ou o próprio logotipo do site. Abaixo dessa superfície está o esqueleto do site: o posicionamento dos botões, abas, fotos e blocos de texto. O esqueleto é projetado com o objetivo de otimizar o arranjo desses elementos para alcançar a máxima eficiência e é a expressão concreta da estrutura mais abstrata do site. Deve definir a disposição dos elementos da interface das páginas do site, e também como os usuários vão de uma página à outra. A estrutura constitui, então, o modo como as diversas características formais e funcionais do site se encaixam. Tais características compõem o escopo do site, uma vez que são definidas a partir dos objetivos pensados para o ele. O escopo é essencialmente estabelecido pela estratégia delimitada para o projeto, apontando especificações das funções necessárias e de que tipo de conteúdo será disponibilizado. Essa estratégia incorpora não apenas o que as pessoas que solicitaram a criação do site desejam conseguir através dele, mas também o que os usuários buscam conseguir nele.

Para Garrett (2002), é evidente que existem mais do que apenas cinco elementos da experiência do usuário, e como qualquer campo especializado, essa é uma área que desenvolveu um vocabulário próprio. A fim de esclarecer dúvidas acerca da terminologia utilizada, definindo que atividades estariam ligadas a cada nível, ele apresenta a dualidade básica da web: web como interface de software (as software interface) e web como sistema de hipertexto (as hypertext system) ${ }^{1}$. Para isso, o autor propõe dividir ao meio os cinco níveis descritos anteriormente e descreve o que deve ser pensado em cada um dos lados, em cada nível.

No lado reservado para a web como interface de software, os designers estão preocupados principalmente com as tarefas - os passos envolvidos no processo e como as pessoas pensam a

\footnotetext{
${ }^{1}$ Tradução de Livia Labate. Disponível em: <http://www.jjg.net>. Acesso em: 10 out. 2008.
} 
fim de completá-los. Nesse lado, o site é planejado como uma ferramenta, ou conjunto de ferramentas, que o usuário utiliza para executar uma ou mais tarefas. Já no lado que pensa a web como sistema de hipertexto, a preocupação principal é a informação - que informações o site oferece e o que isso significa para os usuários. Criar conteúdo hipertextual significa produzir um espaço de informação pelo qual os usuários possam se mover. Uma vez descrita a dualidade da web e como ela se relaciona com os cinco níveis apresentados, o autor propõe o mapeamento em seu modelo do confuso arranjo de termos relacionados à experiência do usuário. Em cada nível, tornam-se claras as preocupações e objetivos de cada etapa nesse tipo de projeto, vistos, nesse momento, da base - mais abstrata -, ao topo - mais concreto.

Os mesmos interesses no nível de estratégia servem aos espaços da interface de software e ao sistema de hipertexto. As necessidades do usuário são as metas para o site que atendem àqueles que o utilizarão. Os estudos sobre usabilidade são bastante importantes nesse nível. $\mathrm{A}$ usabilidade é geralmente considerada como aquilo que garante que um produto seja fácil de usar do ponto de vista do usuário. O atributo principal de um design responsável, para Javier Royo (2008), é que os aparelhos sejam 'usáveis', sendo sempre o usuário o centro das preocupações do designer. Assim, a usabilidade ou capacidade e facilidade de uso de um aparelho, de uma instalação, de um formulário ou de um site é uma característica implícita do campo do design. Segundo Jennifer Preece, Yvonne Rogers e Helen Sharp (2005), as metas de usabilidade podem ser divididas em: eficácia - diz respeito a quanto um sistema é bom em fazer o que se espera dele -; eficiência - ligada ao nível de produtividade no uso do produto -; segurança - implica em proteger o usuário de condições perigosas, prevenindo-o de cometer erros graves -; utilidade define se o sistema fornece um conjunto apropriado de funções que permita aos usuários realizar suas tarefas do modo que desejam -; capacidade de aprendizagem - refere-se a quão fácil é aprender a usar o sistema -; e capacidade de memorização - indica o nível de dificuldade em lembrar como utilizar um sistema.

Cientes das necessidades dos usuários é possível definir como atingir os objetivos estratégicos. Estratégia se transforma em escopo quando se traduz as necessidades do usuário e os objetivos do site em requisitos específicos para quais conteúdos e funcionalidades o site oferecerá aos usuários. No nível de escopo, do lado da interface de software, a estratégia é traduzida em escopo a partir da criação das especificações funcionais: uma descrição detalhada das características do produto, do que o sistema deverá ser capaz de fazer. No lado do sistema de hipertexto, esse plano toma a forma das exigências de conteúdo: definição dos vários elementos do conteúdo que serão disponibilizados, como imagens, animações, vídeos, áudios, gráficos tridimensionais (Nielsen, 2000).

O escopo gera a estrutura no lado do software através do design de interação, no qual é definido como o sistema se comporta em resposta ao usuário. É o momento de definir o modelo conceitual do site a ser projetado, que pode estar focado no conteúdo como lugar a ser visitado ou objeto a ser adquirido (Garrett, 2002). Já na parte do sistema de hipertexto, a estrutura é a arquitetura da informação, que define o arranjo dos elementos de conteúdo no espaço informacional, estabelecendo as conexões entre as unidades básicas desse tipo de estrutura: os nós. Tais estruturas podem ser hierárquicas - em árvore -, matriciais (matrix structures) permitindo que o usuário se mova de um nó a outro em duas ou mais dimensões -, orgânicas/aleatórias - sem qualquer padrão de organização -, ou seqüenciais/lineares (figura 3) (Garrett, 2002; Royo, 2008). Royo (2008) identifica ainda outros dois tipo de estruturas não especificadas por Garrett (2002): as estruturas relacionais - que colhem informações dos usuários e organizam a informação conseguida - e as estruturas contributivas - encontradas em sites que permitem que os usuários participem com mensagens e discussões, que vão aumentando o sistema de ligações.

O nível de esqueleto se divide em três componentes. Nos dois lados é necessário pensar no design da informação enquanto atividade que define como apresentar os dados de modo que as pessoas os compreendam mais facilmente. Estabelecer se a melhor maneira para tornar informações visíveis - "visualizá-los" (Tufte, 1998) - é apresentá-los em um gráfico em fatias ou em barras faz parte desse trabalho. Para projetos de interface de software, o esqueleto também inclui o design da interface. Nesse nível, são estabelecidas as convenções e metáforas que orientarão o usuário na navegação. Já a interface para um espaço informacional é seu design da navegação: o arranjo dos elementos na tela que permite que os usuários se movam pela arquitetura da informação, indicando a eles onde se encontram no site e onde podem ir (Garrett, 2002) $)^{2}$. Para Nielsen (2000), a navegação é pensada para ajudar os usuários a responder a três

\footnotetext{
${ }^{2}$ Sobre esse tema, é importante citar ainda o trabalho de Gui Bonsiepe (1999), que apresenta o projeto de interface para programas de computação como formador de um novo campo do design, uma área híbrida, onde os limites entre design
} 
perguntas fundamentais: "onde estou?" - estabelecendo relação da localização do usuário com a web como um todo e da localização do usuário com a estrutura do site -; "onde estive?" ajudando-o a apreender a estrutura do site e evitando que gastem tempo em páginas já visitadas ; e "aonde posso ir?" - indicando os possíveis caminhos a seguir a partir de sua localização atual. A maioria dos sites utilizam múltiplos sistemas de navegação.Na superfície, tanto no projeto da interface de software quanto do sistema de hipertexto, a preocupação é a mesma: o design visual. Nesse nível, conteúdo, funcionalidades e estética estão juntos para atingir a finalização de um projeto que cumpra as metas dos outros quatro níveis (Garrett, 2002).

O design de websites, enquanto projeto de espaços on-line, constitui-se a partir desses cinco níveis, desde o estratégico, mais abstrato, até o superficial, mais concreto. A construção do site de um periódico científico, e o resultado mais visível do projeto concentrado em seu design visual, estão, assim, profundamente ligados ao entendimento das necessidades do projeto. Quando se trata de documentos eletrônicos na Internet deverá ser levado em consideração não apenas a facilidade com que as pessoas acessam e interpretam as informações, mas também como os computadores localizam e processam os recursos disponíveis. Isso poderá exigir que em diversas situações, no âmbito da comunicação científica, a riqueza de elementos gráficos ou esteticamente atraentes sejam deixados de lado, tendo em vista a priorização do intercâmbio de informações entre máquinas.

Embora os serviços de pesquisa tenham tido um desenvolvimento considerável nos últimos anos, ainda permanecem significativas as limitações relacionadas a questões de interpretação. Atividades bastante simples para usuários não conseguem ser realizadas por máquinas. Como exemplo, poderíamos destacar a interpretação das imagens contidas em documentos, onde a identificação dos elementos contidos na figura é feita sem maiores dificuldades pelo leitor. Um software, contudo, ainda não consegue realizar tal operação. Em um caso como este, será tarefa do web designer indicar atributos que descrevam a imagem a partir de tags ALT (alternative text). No que diz respeito ao conteúdo das páginas, também é possível adicionar meta tags, que são etiquetas HTML que fornecem informações sobre o conteúdo das páginas, essenciais a sites que contenham poucos textos.

Estas questões passam a fazer parte do universo da comunicação científica na medida em que a padronização de esquemas ou modelos de organização de objetos digitais na Internet é um dos aspectos que permite a integração entre pesquisadores, instituições e recursos informacionais relevantes às suas áreas de interesse e atuação. Em fase de consolidação, o processo de edição e publicação on-line abrange aspectos particulares vinculados ao suporte como a disponibilidade de acesso, resgate das informações, critérios de interatividade e navegabilidade. Estes, contudo, devem seguir parâmetros balizados pela tradição e legitimidade do periódico científico impresso: apresentar política editorial, possuir conselho editorial, uma rigorosa revisão de qualidade (peer review), dedicar-se a uma área específica, manter edições regulares, ter ISSN, apresentar instruções aos autores, não ter caráter departamental, para citar alguns.

$\mathrm{Na}$ área acadêmica, onde a construção do conhecimento passa pela citação de fontes, a identificação da literatura é fundamental. Um mesmo identificador aponta para uma obra única, enquanto identificadores distintos constituem publicações diferenciadas. Se tomarmos como referência periódicos científicos que migraram do meio impresso para o eletrônico, vemos que estes detinham um registro International Standard Serial Number (ISSN). Contudo, sua versão online é considerada como uma outra obra, devendo possuir outro registro de ISSN que indique sua edição eletrônica, ou seja, o e-ISSN, como observa-se na nomenclatura do Portal de Periódicos da Coordenação de Aperfeiçoamento de Pessoal de Nível Superior (Capes).

No ambiente de rede, em que o usuário pode consultar um documento citado a partir do próprio objeto que está acessando, a questão da identificação assume papel decisivo, pois colabora no aprimoramento da busca de informações. O Digital Object ldentifier (DOI) é também um identificador persistente e único, associado a um recurso - texto, áudio, vídeo, ou outro material digital - independentemente de sua localização. Segundo Rosenblatt (1997), este pode ser aplicado a objetos de diferentes granularidades, que vão desde uma ilustração a coleções, por exemplo. O sistema é mantido pela International DOI Fundation (IDF) ${ }^{3}$ e respondeu a uma

gráfico e de produto se diluem. Interfaces mediam a interação entre pessoas e máquinas. Para Bonsiepe, é por meio delas que os usuários têm acesso aos sistemas computacionais. Segundo o autor, a relação entre o usuário e o computador não é somente uma relação de comunicação, para troca de informações, mas sim um espaço de ação, uma vez que estes objetos metafóricos mais do que representar uma realidade, constituem uma realidade.

${ }^{3}$ http://www.doi.org/ 
demanda da Association of American Publishers com vistas à proteção dos direitos autorais e facilitação de transações eletrônicas e outras operações similares.

Para a descrição de conteúdo de recursos eletrônicos, um dos padrões que vem se destacando é o Dublin Core (DC) ${ }^{4}$ formado por quinze elementos: (1) Title, nome dado ao recurso; (2) creator, responsável pelo conteúdo do recurso; (3) subject, assunto sobre o qual o conteúdo do recurso versa; (4) description, breve descrição do conteúdo do recurso; (5) publisher, responsável pela publicação do conteúdo do recurso; (6) contributor, outros responsáveis por contribuir com o conteúdo do recurso; (7) date, data de um evento no ciclo de vida do recurso; (8) type, natureza ou gênero do conteúdo do recurso; (9) format, formato físico ou digital do recurso; (10) identifier, referência única para o recurso dentro de um dado contexto (URI); (11) source, referência para um recurso do qual o recurso atual é derivado; (12) language, linguagem do conteúdo do recurso; (13) relation, referência para um recurso relacionado ao recurso atual; (14) coverage, escopo do conteúdo do recurso; (15) rights, informações sobre quem mantém direitos sobre o recurso. (DCMI Metadata Terms, 2007)

O projeto atende ao uso de leigos e especialistas e seus elementos apresentam uma semântica universal. Ao disseminar um conjunto de descritores de entendimento compartilhado, $o$ DC facilita a unificação de dados padronizados e amplia a interoperabilidade potencial entre disciplinas. Além disso, é flexível e extensível para codificar estrutura e semântica mais elaboradas, presentes em padrões de descrição mais complexos. Diferentes métodos podem ser utilizados no registro e transferência de metadados Dublin Core.

Embora os metadados sejam apontados como uma das principais vantagens para ampliar a visibilidade dos periódicos científicos, a mesma flexibilidade que permite sua utilização múltipla resulta também em interpretações diferentes. Isso implica em um uso às vezes desordenado ou até mesmo conflitante entre projetos distintos, sobretudo nos mecanismos de qualificação necessários para fornecer maior precisão semântica aos elementos do DC. Grupos de trabalho vinculados ao Dublin Core vêm desenvolvendo qualificadores ${ }^{5}$ com vistas à adoção de uma linguagem semanticamente semelhante. Recomendado pela comunidade científica e pelo mercado empresarial, o DC - se adotado -, oferece condições para que mecanismos de busca e recuperação de informações sejam capazes de "compreender" metadados semânticos, propiciando resultados mais precisos.

\section{Arquivos abertos, acesso livre e indexação}

Uma das questões relevantes relacionadas à disseminação da informação científica na Internet é o modo de acesso, destacando-se dois modelos principais: a revista científica por assinatura (acesso restrito) e o acesso livre (acesso aberto/open acess). Este último relaciona-se a duas iniciativas, que são a Open Archives Iniciative (OAI), ${ }^{6}$ que surgiu com a Convenção de Santa Fé (1999) e o Movimento de Acesso Livre, ${ }^{7}$ iniciado com a Declaração de Budapest (2001). Ambos visam o acesso livre e gratuito à informação científica. ${ }^{8} \mathrm{O}$ protocolo Open Archives Initiative Protocol for Metadata Havesting (OAI-PMH) permite a transferência dos dados entre diferentes sistemas associados à iniciativa, assegurando a interoperabilidade. Entre os princípios do Acesso Aberto destacam-se: sistema de armazenamento a longo prazo, auto-publicação, política de gestão com normas de preservação de objetos digitais, acesso livre - também para coleta e replicação de metadados, uso de padrões e protocolos que visam a troca de informações entre bibliotecas eletrônicas, e o uso de softwares de fonte aberta (open source).

Está ligado a esta iniciativa o programa Open Journal Systems (OJS) da British Columbia University. No Brasil, foi traduzido e adaptado pelo Instituto Brasileiro de Informação em Ciência e Tecnologia (IBICT), originando o Sistema Eletrônico de Editoração de Revistas (SEER), disponibilizado em 2004 aos editores científicos. Por meio do OJS/SEER, o periódico ganha rapidez e transparência nos procedimentos editoriais, desde a submissão, avaliação, até a

\footnotetext{
${ }^{4}$ http://dublincore.org/

${ }^{5}$ http://www.dublincore.org/documents/2000/07/11/dcmes-qualifiers/

${ }^{6}$ http://www.openarchives.org

${ }^{7}$ http://www.soros.org/openaccess/

${ }^{8}$ É importante situar esta iniciativa dentro de um esforço internacional em romper com entraves econômicos do mercado editorial ao defender a livre disseminação dos resultados de pesquisas financiadas com recursos públicos. A atual transição entre os suportes impresso e eletrônico ainda reproduz boa parte dos modelos tradicionais vigentes no financiamento das revistas científicas, entre elas, o pagamento da publicação pelo autor e/ou leitor (Briquet de Lemos, 2006).
} 
publicação on-line e indexação. Ao utilizar o protocolo OAI-PMH, ele possibilita o intercâmbio de metadados com base no DC, ferramentas de apoio à pesquisa, assim como mecanismos para preservação dos conteúdos.

Outra ação é o projeto SciELO (Scientific Eletronic Library Online), desenvolvido pela Fundação do Amparo à Pesquisa do Estado de São Paulo (FAPESP), Conselho Nacional de Desenvolvimento Científico e Tecnológico (CNPq) e Centro Latino Americano e do Caribe de Informação em Ciências da Saúde (BIREME). Trata-se de um agregador não-comercial para consulta a periódicos brasileiros e estrangeiros, selecionados a partir de critérios internacionais de qualidade. A rede ibero-americana de acesso aberto, liderada pelo Brasil e pelo Chile, publica indicadores bibliométricos similares aos do Journal Citation Reports (JCR) do Institute for Scientific Information (ISI). Apresenta sistema de metadados, links com outras fontes de informação, estatísticas de uso e citações e fator de impacto. No Brasil, serve como instância seletiva de indexação complementar, favorecendo a entrada dos periódicos nacionais em indicadores internacionais de referência.

Segundo Packer e Meneghini (2006:253-254), o número médio de leitura ou de artigos acessados (downloads) é um dado fundamental na visibilidade de um periódico na web. Quanto maior este número, mais visível torna-se a publicação on-line. Potencializar este indicador é aumentar o número de incomming links para o periódico. Ou seja, participar de coleções internacionais de qualidade implica em usufruir do seu sistema de links. As revistas das coleções SciELO apresentam uma média de dois milhões de visitas por mês, muitas delas provenientes de índices e buscadores como Literatura Latino-americana e do Caribe em Ciências da Saúde (LILACS), Web of Science, Portal Capes, PubMed, entre outros. O fator de impacto da maioria dos periódicos SciELO aumentou a partir da existência da coleção.

Walker (2002) discute o valor dos links, evidenciando como se relacionam à visibilidade $\mathrm{e}$ influenciam na composição topológica da rede. Ainda que todos os nós da rede estejam disponíveis em termos de organização e linguagem, alguns sites são mais acessíveis do que outros em função da quantidade de incomming links a eles vinculados. Mecanismos de busca como o Google utilizam a linkagem como sistema de valoração. Os portais, repositórios e mecanismos de busca detêm uma grande quantidade de links, com duas funcionalidades principais: expressam associações semânticas ou de estrutura. (Obendorf \& Weinreich, 2003) Há mais links estruturais que associativos na web, em geral ligados a barras de navegação. No âmbito dos periódicos, a presença de citações de documentos disponíveis on-line, passíveis de serem acessados, é a principal vantagem do artigo eletrônico em relação ao impresso. No estado atual da apropriação tecnológica, que reflete diretamente os valores da comunidade científica, ainda é raro encontrar outros recursos multimídia ou mesmo parágrafos articulados em modo hipertextual em um artigo científico.

O trabalho de edição e publicação de periódicos científicos impressos mantém-se como referencial para a orientação das práticas editoriais destinadas à publicação na Internet, até mesmo para aqueles editores que já concluíram a passagem da publicação impressa para a online. Avaliando a primeira fase da utilização da tecnologia informática na produção de revistas científicas on-line, viu-se a proliferação das publicações disponíveis em $\mathrm{PDF}^{9}$, na maioria das vezes, uma mera transposição do impresso para a tela. Nessa fase, ao publicar um título em meio eletrônico e disponibilizá-lo na web, os editores científicos procuravam maiores rapidez na busca de informação, facilidade de acesso e agilidade na divulgação dos resultados das pesquisas, chance igualitária de acesso aos cientistas mais dispersos geograficamente, entre outros benefícios. Um exemplo das vantagens iniciais da circulação eletrônica dos artigos é que esta aumenta em cerca de $336 \%$ as citações on-line em relação à mesma fonte impressa (Lawrence, 2007).

Nesse sentido, o surgimento dos sistemas de indexação e os índices de citação colaborou para o aumento da visibilidade dos títulos. Segundo Ferreira (2007), o crescimento do número de revistas, a ampliação bibliográfica bem como o desenvolvimento de novas tecnologias para gerenciamento e organização de conteúdos implicaram novas formas de acesso e disseminação da informação acarretando o surgimento de dois tipos distintos de serviços: os index e/ou abstracts (sistemas de indexação ou resumo) e os citation index (índice de citações). Ao oferecer

\footnotetext{
${ }^{9}$ Portable Document Format - PDF -, é um tipo de arquivo gerado a partir de documentos editáveis. Pode ser aberto em diferentes máquinas, preservando sua diagramação, fonte, tamanho, etc. É bastante utilizado para disponibilização de conteúdo científico em meio eletrônico, apesar de sua formatação, normalmente, manter a estrutura de documentos impressos.
} 
maior acessibilidade e visibilidade à produção científica internacional, estes passaram a orientar e fornecer os parâmetros e os indicadores de qualidade vigentes e aceitos pela coletividade científica até a atualidade.

Entretanto, apesar dos inúmeros ganhos proporcionados pela utilização da tecnologia informática, pouco se procurou propor em relação ao processo de produção e assimilação dos conteúdos na Internet. Passamos agora para um outro momento dessa utilização, onde se buscam novos usos do suporte digital e das publicações em rede. Das interfaces criadas em função do texto impresso, compostas por página de título, cabeçalhos, numeração regular, sumários, notas, referências cruzadas, base conceitual dos arquivos em PDF disponíveis na rede, o hipertexto retoma e transforma essa configuração, chegando-se ao desenvolvimento de interfaces mais adequadas ao modo de assimilação da informação no novo meio.

\section{Desafios para editores e designers}

O formato final de um periódico é resultado de um processo editorial que envolve rotinas produtivas. Existem três tipos de editoras que lidam com publicações impressas: as editoras universitárias, as editoras institucionais - de associações ou entidades científicas e profissionais e as editoras comerciais. A estrutura da editora irá influenciar na sistemática e agilidade do processo, interferindo na qualidade editorial e formal do material produzido.

As diferentes áreas do conhecimento têm suas particularidades no encaminhamento do processo editorial. No meio acadêmico, de modo geral, a produção dos periódicos científicos é gerenciada por comissões editoriais vinculadas a cursos ou departamentos, programas de pósgraduação, associações, etc. O fato dos periódicos científicos dirigirem-se prioritariamente a leitores altamente especializados em suas áreas de conhecimento exige uma avaliação rigorosa do material a ser publicado. Com isso, tem-se uma interdependência entre os responsáveis pela edição e a comunidade científica. Uma vez que freqüentemente encontramos editores especialistas em uma área do conhecimento, mas que não têm domínio do processo de produção editorial, é importante a constituição de comissões editoriais de modo que se possa contar com profissionais que também dominem este campo. O vínculo com uma editora, neste sentido, pode facilitar em grande parte o processo.

Conforme aspectos sistematizados e discutidos ao longo deste artigo, observa-se que um conjunto de novos elementos exige dos editores o planejamento, desenvolvimento e distribuição das revistas de modo a assegurar sua visibilidade na Internet. A produção de revistas eletrônicas vem adaptando, desenvolvendo e sedimentando o fluxo editorial de periódicos científicos. Nesse sentido, destacam-se aplicativos como o OJS/SEER que abarca tanto o processo de edição e seus fluxos, como a publicação dos artigos. Ao fomentar a transparência na avaliação pelos pares, a integração dos resultados de busca e o acesso irrestrito, a divulgação e disseminação, a publicação e comunicação através dos recursos hipertextuais, a indexação e os serviços de informação que asseguram maior visibilidade aos periódicos, o armazenamento e a preservação a longo prazo, bem como a redução de custos e a preservação dos direitos autorais, a utilização do sistema vem crescendo de maneira significativa do Brasil e na América Latina ${ }^{10}$.

É importante salientar que as etapas de produção editorial de uma revista científica mantêm características particulares em relação a outros gêneros editoriais. Divididas de maneira geral em planejamento editorial, fluxo editorial e circulação (Gruszynski, Golin e Castedo, 2008), o projeto e realização de cada uma dessas fases interferem nas decisões a serem tomadas no design desse tipo de publicação. De modo sintético ${ }^{11}$, essas etapas envolvem:

\section{Planejamento editorial}

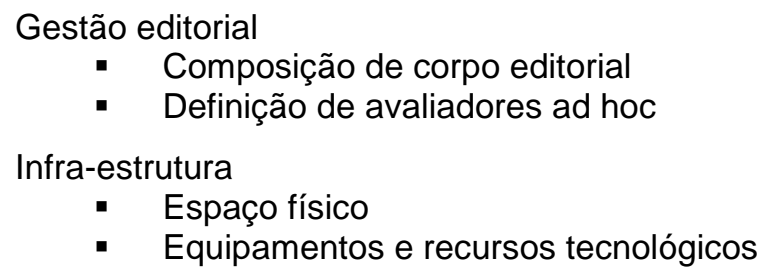

Serviços técnicos especializados

\footnotetext{
${ }^{10} \mathrm{Em} 4$ de dezembro de 2008 constam 565 revistas utilizando o OJS/SEER no Brasil registradas junto ao portal do lbict http://seer.ibict.br/index.php?option=com_mtree\&ltemid=109

${ }^{11}$ Cf. proposta completa em Gruszynski, Golin, e Castedo (2008).
} 
- Recursos financeiros para contratação

- Parcerias, fomento ou patrocínio

Política editorial

- Título e subtítulo do periódico

- Área de conhecimento abrangida

- Projeto editorial

Critérios de edição (decorrentes da política editorial)

- Diretrizes para autores

- Número mínimo de textos por volume

- Organização/edição dos conteúdos em ordem:

- Cronograma/prazos por etapa

\section{Fluxo editorial}

Edição de texto

- Avaliação pelos pares

- Mediante aceite, revisão ortográfica e gramatical

- Mediante aceite, normalização técnica

Elementos que devem constar no site

Dados de identificação do periódico

Instituição responsável

Dados sobre gestão e política editorial

Dados sobre circulação

Sumário do fascículo

Expediente

Elementos que devem constar no artigo

Referentes à autoria

Níveis hierárquicos de texto

Dados de identificação do artigo

Edição de layout

- Arquitetura da informação e interface do site

Consistência entre as páginas

Tipos de recursos utilizados pelos artigos

Formato dos fascículos e artigos

Sistema de busca

Ferramentas contextuais

Acessibilidade

- Diagramação do fascículo/artigos

- Revisão de provas

- Disponibilização on-line/publicação

\section{Circulação}

Regularidade

- Periodicidade

- Continuidade

Distribuição - Formas de acesso

- Livre (protocolo OAI-PHM)

- Aberto por site próprio

- Mala direta

- Assinatura

- Disponível em outro formato

Difusão

- Presença em bases de dados

De textos completos / Referenciais / De citações

- Estatísticas de acesso e fator de impacto

Se, por um lado, a evolução tecnológica vem facilitando em muitos aspectos a edição de periódicos científicos, por outro, novos desafios se colocam, exigindo das comissões editoriais um movimento permanente visando dar credibilidade e visibilidade às edições. No campo científico, a normalização atua como uma atividade reguladora, que busca facilitar a transferência de informações ao unificar formas e procedimentos. Ainda que a qualidade de um periódico científico 
dependa fundamentalmente da qualidade de seus conteúdos, sua significação passa pela materialidade dos suportes. A qualificação das características formais da publicação, deste modo, contribui para a consolidação e credibilidade de uma revista.

\section{Considerações finais}

O processo de edição de um periódico científico eletrônico exige que se assegure a qualidade dos conteúdos publicados tendo como referência os valores das diferentes áreas da ciência, dentro de um sistema de comunicação que está em permanente modificação. A introdução das tecnologias digitais vem alterando substancialmente padrões e rotinas consolidadas ao longo do tempo, diluindo fronteiras entre a comunicação formal e informal de resultados de pesquisa, sobretudo através dos serviços disponíveis na Internet como e-mail, grupos de discussão, fóruns, blogs, etc.

Nesse contexto, o web design, a acessibilidade e a otimização de recursos tendo em vista mecanismos de busca, assumem papel fundamental para que as revistas científicas cumpram seu papel na divulgação dos resultados de pesquisas originais. Neste momento de intensas alterações nos processos e formas de circulação do conhecimento, as tensões existentes entre o conhecido mundo impresso, e seus pacotes determinados de informação, e o espaço on-line como um contínuo informativo se intensificam. Questões arraigadas, como o direito autoral cedido aos editores e a exclusividade de publicação, são redimensionadas neste ambiente, assim como a própria velocidade de validação e circulação do conhecimento. Ainda que o periódico eletrônico reproduza as rotinas que abalizaram sua reputação e credibilidade na cultura letrada, verifica-se cada vez mais, no cenário digital, a mutação do próprio conceito deste tipo de publicação no ambiente em rede.

A busca por qualidade e credibilidade de uma publicação de referência mantém-se relacionadas a visibilidade alcançada pelo título. Como discutido neste trabalho, depende também da capacidade de ser acessado em bases de dados e índices, o que se relaciona diretamente com a atividade de design.

\section{Referências}

Briquet de Lemos, A. Periódicos eletrônicos: problema ou solução? Disponível em: <http://www.briquetdelemos.com.br/briquet/briquet_lemos7.htm>. Acesso em: 26 mar. 2006.

Chartier, R. 1996. Do livro à leitura. In: CHARTIER, R. Práticas de leitura. São Paulo, Estação Liberdade, p.77-105.

DCMI Metadata Terms. Disponível em: <http://dublincore.org/documents/dcmi-terms/\#H2>. Acesso em: 09 jan. 2007.

Ferreira, S. M. S. P. Modesto, F.; Weitzel, S. R. Comunicação científica e o protocolo OAI: uma proposta na área de ciências da comunicação. Disponível em: <http://www.intercom.org.br/papers/congresso2003/pdf/2003_ENDOCOM_TRABALHO_ferreira .pdf>. Acesso em: 29 mar. 2006.

Ferreira, S. M. S. P. 2007. Fator de impacto da produção científica da área de ciências da comunicação: um longo caminho a ser percorrido. In: Pinho, J. B. (ed.) Comunicação Brasileira no Século XXI - Intercom: ação, reflexão. São Paulo: Intercom, p. 125-153. (Coleção Verdeamarela, vol.2 - A clava forte)

Frascara, J. 2006. El Diseño de Comunicación. Buenos Aires: Infinito.

Garrett, J. J. 2002. The elements of user experience: user centered design for the web. New York/Berkeley: Aiga/New Riders.

Gruszynski, A. C. 2007. A imagem da palavra: retórica tipográfica na pós-modernidade. Teresópolis: Novas Idéias.

Gruszynski, A. C.; Golin, C.; Castedo, R. C. 2008. Produção editorial e comunicação científica: uma proposta para edição de revistas científicas. E-Compós, Brasília, v.11, n.2. Disponível em: http://www.e-compos.org.br. Acesso em: 5 fev. 2009.

Helfand, J. 1996. Six Essays on Design and New Media. New York: William Drenttel.

Heller, S.; Drennan, 1997. D. The Digital Designer: the graphic artist's guide to the new media. New York: Watson-Guptill Publications. 
Lawrence, S. Free online availability substantially increases a paper's impact. Nature Debate. Disponível em: <http://www.nature.com/nature/debates/e-access/Articles/lawrence.html>. Acesso em: 09 jan. 2007.

Meadows, A. J. 1999. A Comunicação Científica. Brasília: Briquet de Lemos.

Nielsen, J. 2000. Projetando websites. Tradução de Ana Gibson. Rio de Janeiro: Elsevier.

Obendorf , H.; Weinreich, H. Comparing Link Marker Visualization Techniques - Changes in Reading Behavior. WWW 2003, May 20-24, 2003, Budapest, Hungary. Disponível em: <http://www2003.org/cdrom/papers/refereed/p391/p391-obendorf.html>. Acesso em: 9 jan. 2007.

Oslon, D. 1997. O mundo de papel: as implicações conceituais e cognitivas da leitura e da escrita. São Paulo: Ática.

Packer, A. L.; Meneghini, R. 2006. Visibilidade da produção científica. In: Poblacion, Dinah Aguiar (org). Comunicação \& produção científica: contexto, indicadores e avaliação. São Paulo: Angellara, p. 237-259.

Preece, J.; Rogers, Y.; Sharp, H. 2005. Design de interação: além da interação homemcomputador. Tradução de Viviane Possamai. Porto Alegre: Bookman.

Rosenblatt, B. 1997. Solving the dilemma of copyright protection online. The Journal of Eletronic Publishing, v. 3, n. 2, dez. Disponível em: <http://www.press.umich.edu/jep/03-02/doi.html>. Acesso em: 8 jan. 2007.

Royo, J. 2008. Design digital. Tradução de Osvaldo Antonio Rosiano. São Paulo: Edições Rosari.

Tufte, E. R. 1998. Envisioning information. Connecticut: Graphics Press.

Vigner, G. 1988. Intertextualidade, norma e legibilidade. In: Galves, C.; Orlandi, E.; Otoni, P. O texto: escrita e leitura. Campinas, SP: Pontes.

Walker, J. 2002. Links and Power: The Political Economy of Linking on the Web. Proceedings of Hypertext 2002. Baltimore: ACM Press, p. 78-79. Disponível em: $<$ http://jilltxt.net/txt/linksandpower.html>. Acesso em: 10 jan. 2007. 